\title{
Mitochondrial bioenergetics of testicular cells from the domestic cat (Felis catus)-A model for endangered species
}

\author{
Paula Mota ${ }^{\mathrm{a}, 1}$, Sandra Amaral ${ }^{\mathrm{a}, 1}$, Luís Martins ${ }^{\mathrm{a}}$, Maria de Lourdes Pereira ${ }^{\mathrm{b}}$, \\ Paulo J. Oliveira ${ }^{\mathrm{a}}$, João Ramalho-Santos ${ }^{\mathrm{a}, *}$ \\ a Center for Neuroscience and Cell Biology, Department of Zoology, University of Coimbra, Largo Marquês de Pombal, 3004-517 Coimbra, Portugal \\ ${ }^{\mathrm{b}}$ Department of Biology/CICECO, University of Aveiro, Campus Universitário de Santiago, 3810-193 Aveiro, Portugal
}

\section{A R T I C L E I N F O}

Article history:

Received 5 November 2008

Received in revised form 6 January 2009

Accepted 30 January 2009

Available online $\mathrm{xxx}$

\section{Keywords:}

Domestic cat

Carnivores

Bioenergetics

Mitochondria

Testis

Germ cells

Age

Toxicology

\begin{abstract}
A B S T R A C T
Efficient spermatogenesis relies on the balance between energy production and expenditure, and thus depends on mitochondrial function. Our goal was to characterize testis mitochondria isolated from the domestic cat for their future use as a model for endangered felids. Respiration parameters were monitored with a Clark-type oxygen electrode, and the mitochondrial transmembrane potential $(\Delta \Psi)$ was estimated with a $\mathrm{TPP}^{+}$electrode. Testis mitochondria are shown to require low oxygen consumption to generate approximately the same maximum $\Delta \Psi$ as other tissues. We also found differences between young and adult cats suggesting a less efficient phosphorylation system in the first group. Furthermore, an interpolation equation of the relation between maximum $\Delta \Psi$ and age allowed the prediction of the expected $\Delta \Psi$ at each age, as well as possible deviations. The results generate a novel model from a carnivore to further test drugs or environmental contaminants (such as pesticides and herbicides), many of which act on mitochondria and may interfere with the reproduction of wild animals.
\end{abstract}

(ㄷ) 2009 Elsevier Inc. All rights reserved.

\section{Introduction}

Mammalian spermatogenesis is a continuum of dramatic biochemical events and morphological alterations starting with a relatively undifferentiated diploid stem cell, the primitive type A spermatogonium, and ending with a highly differentiated haploid cell, the spermatozoon [1].

Domestic cat spermatogenesis has been the target of recent research, not due to fertility problems in the cat itself, but because of its possible use as a model for endangered wild felids with reduced fertility, due to the taxonomic proximity (family Felidae). Spermatogenic stages [2], efficiency/alterations of spermatogenesis $[3,4]$, proliferation/apoptosis during the spermatogenic cycle [5] and abnormal sperm morphology/DNA nuclear content [6] are some of the aspects that have been analyzed in the cat. However, all processes required for suitable spermatogenesis rely on the balance between energy production and expenditure, and thus are dependent on testicular bioenergetic parameters.

\footnotetext{
* Corresponding author. Tel.: +351 239855 760; fax: +351 239855789.

E-mail address: jramalho@ci.uc.pt (J. Ramalho-Santos).

${ }^{1}$ Grant support: Paula C.C.R. Mota and Sandra C.G. Amaral were supported by the Portuguese Foundation for Science and Technology with PhD scholarships (SFRH/BD/23643/2005 and SFRH/18734/2004, respectively).
}

Mitochondria have been recognized as the cell powerhouses for half a century [7]. Dissimilarities in mitochondria from distinct species and tissues in the same organism reflect the relative importance of the metabolic pathways to a given cell or organism [8]. With the exception of glycolysis, mitochondrial-based oxidative phosphorylation is thus paramount for energy production, and any mitochondrial impairment may influence the outcome of spermatogenesis.

Mitochondria generate energy by using the mitochondrial respiratory chain (MRC) a process in which substrates such as pyruvate and fatty acids are oxidized by a sequence of cytochromes with increasing redox potential, releasing small amounts of energy at each step. The MRC actively extrudes protons from the mitochondrial matrix to the inter-membrane space, and since the inner mitochondrial membrane is proton-impermeable, energy is stored as a chemical and electrical gradient ( $\Delta \mathrm{pH}$ and $\Delta \Psi$, respectively), with the matrix negatively charged. The proton gradient is then used to synthesize ATP from ADP at the enzyme ATP synthase [9]. Besides energy production, mitochondria also play an important role on ROS production and related signaling pathways (for review see [7]) and on apoptosis (for review see [10]), which may also have a special interest for germ cell development and regulation.

There is a wide spectrum of environmental toxic agents with deleterious effects on reproduction. Pesticides used to control noxious insects, such as DDE, a metabolite of DDT, were found to cause

0890-6238/\$ - see front matter @ 2009 Elsevier Inc. All rights reserved. doi:10.1016/j.reprotox.2009.01.008 
testis toxicity via mitochondria [11]. Moreover, mercury, a heavy metal, was found to increase mitochondrial oxygen consumption in resting conditions (State 4 respiration) associated with a decrease in mitochondrial electrical potential in hepatoma cells [12], and had the same effects on sperm respiration [13]. These environmental contaminants were already found in tissues of endangered species such as the Florida panther (Felis concolor coryi) and have been correlated with changes in reproductive parameters such as low sperm concentration, low motility and high percentage of abnormal sperm [14]. Other studies emphasize the importance of accumulation of these substances in fish and small mammals that ultimately became prey to the big cats, acting as bioaccumulators [15].

Therefore, it was our objective to characterize testis mitochondria isolated from the domestic cat (Felis catus) with the purpose of considering their future use as a biological model for endangered felids. To our knowledge, this is also the first study on mitochondrial bioenergetics in testicular cells from a carnivore.

\section{Material and methods}

\subsection{Materials}

All chemicals were obtained from Sigma, St Louis, MO, USA, unless otherwise described.

\subsection{Isolation of testis mitochondria}

Testis from male domestic cats (Felis catus) aged 6-108 months were obtained from private clinics following routine castration procedures. The animals were of mixed breeds (Common European) and presented good health, as evaluated by a general health exam previous to surgery, with the exception of one animal infected with Feline immunodeficiency virus. The animals analyzed were divided in two groups: the young group included animals between 6 and 12 months of age $(n=10)$ inclusive, and represents pubertal cats in several stages of spermatogenic development that range from having only spermatogonia to tubules with complete spermatogenesis. The adult group includes animals from 13 to 108 months $(n=11)$ and represents animals with fully active reproductive function [16]. Once collected the testis and epidydimides were immediately put on ice and weighed.

Isolation of testicular mitochondria was carried out as described [17]. Briefly, testes were decapsulated and finely minced several times in an ice-cold isolation medium containing $250 \mathrm{mM}$ sucrose, $0.2 \mathrm{mM}$ EGTA, $0.1 \mathrm{mM}$ EDTA, $5 \mathrm{mM}$ HEPES$\mathrm{KOH}$ ( $\mathrm{pH} 7.4$ ) and $0.1 \%$ defatted BSA (bovine serum albumin). The minced blood-free tissue was then resuspended in isolation medium and homogenized with a tightly fitted Potter-Elvjjem homogenizer (Teflon:glass pestle). The homogenate was then centrifuged at $2500 \times \mathrm{g}$ for $10 \mathrm{~min}$ (Sorvall RC-5C, Plus, SS 34 rotor, $4-8^{\circ} \mathrm{C}$ ). The resulting supernatant was centrifuged at $10,000 \times \mathrm{g}$ for $10 \mathrm{~min}$. The pellet (mitochondrial fraction) was resuspended using a paint brush and repelleted twice at $10,000 \times g$ for $10 \mathrm{~min}$. EGTA, EDTA and defatted BSA were omitted from the washing medium. Mitochondrial protein content was determined by the biuret method, calibrated with BSA.

\subsection{Measurement of mitochondria isolation yield using citrate synthase activity}

Citrate synthase activity was determined to indirectly evaluate the number of mitochondria present in isolated fractions [18]. Briefly, frozen-thawed testis mitochondria $(50 \mu \mathrm{g})$ were incubated with $1 \mathrm{ml}$ of Tris-based media $100 \mathrm{mM}$ Tris $200 \mu \mathrm{M}$ Acetyl-CoA and $200 \mu \mathrm{M}$ DTNB (5,5V-dithiobis-2-nitrobenzoic acid)]. The absorbance of the suspension was continuously measured at $412 \mathrm{~nm}$ under stirring and at $30^{\circ} \mathrm{C}$. After a baseline setting, $100 \mu \mathrm{M}$ oxaloacetate was added. After 100 s of reaction $25 \mu \mathrm{l}$ of $10 \%$ Triton X-100 was added to measure total citrate synthase activity. In this protocol, we measured the formation rate of a colored product resulting from the condensation of DTNB and coenzyme A. Our results showed no significant differences in citrate synthase activity, thus indicating that no significant differences in the number of mitochondria per milligram of protein existed in the different groups tested (Table 1).

\subsection{Mitochondrial oxygen consumption}

Oxygen consumption of isolated testis mitochondria was monitored polarographically with a Clark-type oxygen electrode [19] connected to a suitable recorder in a 2-ml thermostated water-jacketed closed chamber with magnetic stirring, at $27^{\circ} \mathrm{C}$. The standard respiratory medium consisted of $65 \mathrm{mM} \mathrm{KCl}$

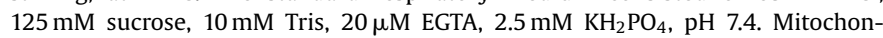
dria were suspended at a concentration of $0.8 \mathrm{mg} / \mathrm{ml}$ in the respiratory medium and were energized with both glutamate-malate and succinate as substrates. Glutamate-malate indirectly supplies electrons to mitochondrial complex I and succinate directly reduces complex II. Rotenone ( $3 \mu \mathrm{M})$ was used to inhibit complex I and avoid reverse flow of electrons from complex II to complex I. A small amount of ADP $(25 \mu \mathrm{M})$ was added to induce state 3 respiration. State 4 respiration corresponds to resting oxygen consumption after ATP production. Respiratory control ratio (RCR) and $\mathrm{ADP} / \mathrm{O}$ ratios were calculated, according to Chance and Williams, in mitochondria energized with glutamate-malate or succinate [20].

\subsection{Measurement of mitochondrial transmembrane potential}

Mitochondria were energized with $5 \mathrm{mM}$ succinate (plus rotenone), that results in mitochondrial energization by complexes II, III and IV, or $5 \mathrm{mM}$ glutamate-malate, which leads to mitochondrial energization by complexes I, III and IV. The mitochondrial transmembrane potential $(\Delta \Psi)$ was estimated with a tetraphenyl phosphonium-selective $\left(\mathrm{TPP}^{+}\right)$electrode according to the equation of Kamo et al. without correction for the "passive" binding contribution of $\mathrm{TPP}^{+}$to the mitochondrial membranes [21]. A matrix volume of $1.1 \mu \mathrm{l} / \mathrm{mg}$ protein was assumed. Reactions were carried out, at $27^{\circ} \mathrm{C}$, in $1 \mathrm{ml}$ of the reaction media $(65 \mathrm{mM} \mathrm{KCl}, 125 \mathrm{mM}$ sucrose, $10 \mathrm{mM}$ Tris, $20 \mu \mathrm{M}$ EGTA, $2.5 \mathrm{mM} \mathrm{KH}_{2} \mathrm{PO}_{4}$, pH 7.4) with $2 \mu \mathrm{M} \mathrm{TPP}{ }^{+}$, and $0.8 \mathrm{mg}$ mitochondria.

\subsection{Testicular tissue histological analysis}

Cat testes ranging from 6 to 24 months were immersion-fixed in Bouin's solution for $24 \mathrm{~h}$. The testis were embedded in paraffin wax and cut into $5 \mu \mathrm{m}$ thick cross sections. The tissue sections were dewaxed, hydrated and stained with hematoxylin and periodic acid/Shiff reagent for histomorphometric analysis.

Table 1

Bioenergetic parameters analyzed for the cat testicular cells.

Mitochondria energized with glutamate + malate

Maximum potential ( $\Delta \Psi$ in $\mathrm{mV}$ )

ADP-induced depolarization $(\Delta \Psi$ in $\mathrm{mV}$ )

Repolarization potential $(\Delta \Psi$ in $\mathrm{mV})$

Lagphase (in seconds)

Mitochondria energized with succinate

Maximum potential $(\Delta \Psi$ in $\mathrm{mV})$

ADP-induced depolarization $(\Delta \Psi$ in $\mathrm{mV})$

Repolarization potential ( $\Delta \Psi$ in $\mathrm{mV}$ )

Lagphase (in seconds)

State 3 respiration (natoms/mg protein $/ \mathrm{min}$ )

State 4 respiration (natoms/mg protein $/ \mathrm{min}$ )

RCR

ADP/O

Citrate synthase activity ( $\mu \mathrm{mol} / \mathrm{min} / \mathrm{mg}$ protein)
$-205.53 \pm 2.08$

$-19.61 \pm 0.88$

$-200.57 \pm 2.16^{*}$

$41.40 \pm 2.64$

$-210.94 \pm 1.82^{*}$

$-21.81 \pm 1.08$

$-209.58 \pm 1.72^{* *}$

$31.36 \pm 1.96$

$22.67 \pm 1.59$

$10.24 \pm 1.29$

$2.21 \pm 0.21$

$1.96 \pm 0.12$

$0.449 \pm 0.021$

$\Delta \Psi$, mitochondrial electric potential; RCR, respiratory control ratio; ADP/O, nanomoles of ADP phosphorylated by the reduction of 1 nanoatom of oxygen.

${ }^{*} P<0.05$.

** $P<0.01$. 

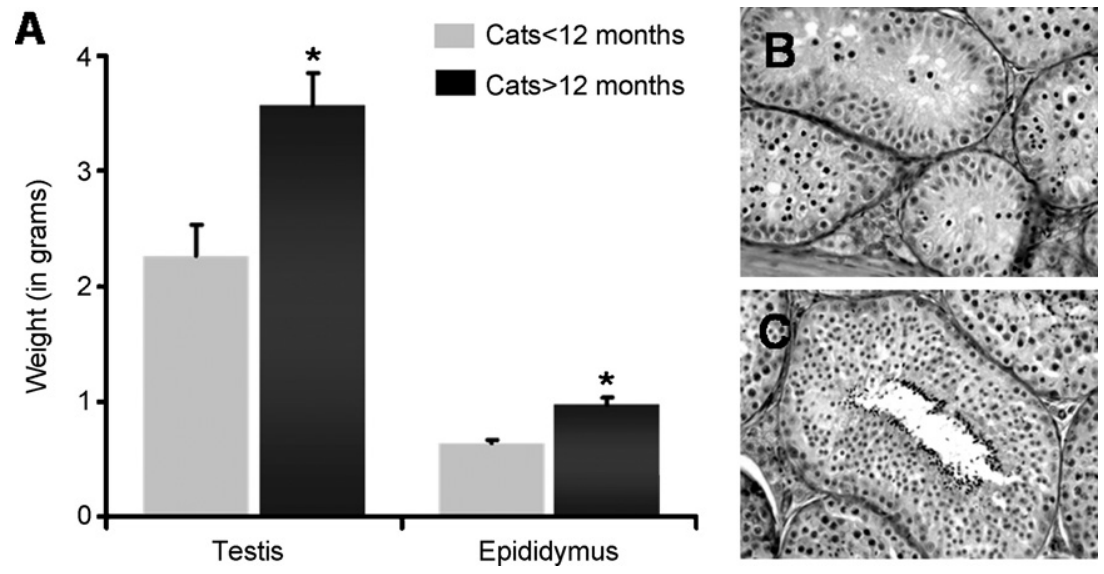

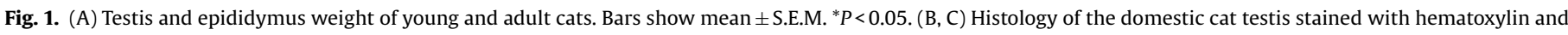

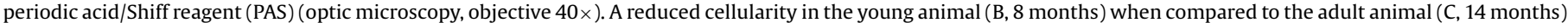
is observable.

\subsection{Statistical analysis}

All statistical analyses were performed using the SPSS (Statistical Package for the Social Sciences Program), version 13.00, software for windows (SPSS Inc., Chicago, IL, USA). All variables were checked for normal distribution. Results are presented as mean \pm S.E.M. of the number of experiences indicated. Multiple comparisons were performed using the Mann-Whitney $U$-test for the non-normal variables and the $T$-test for the normal variables. $P<0.05$ was considered significant. Bivariate correlation $(r)$ in different groups was evaluated by calculating the Pearson correlation coefficient with a two-tailed significance.

\section{Results}

Our aim in this study was to characterize the testis as a whole, with all the different cell types necessary for the development of spermatogenesis, and not to particularize between different cell types. Mainly because this is the first study in mitochondria from the testis of the cat, or any other carnivore, and secondly because of limitations presented by the amount of mitochondria in the testis ( $\mathrm{mg}$ of mitochondrial protein/ml of pellet isolated), approximately $6-8 \mathrm{mg}$ of mitochondrial protein for young and adult group respectively, that made it impossible to divide according to cell type. We also could not join testis of several animals due to different genetic backgrounds and age/spermatogenic development.

\subsection{Testis characterization according to age}

The adult animals showed an increased testis and epididymus weight when compared to young animals ( $p<0.05$; Fig. $1 \mathrm{~A}$ ) due to an increase in testis cellularity as observed with histological analysis (Fig. 1B and C). Irrespectively of this increase of cellularity, our results did not shown any significant differences between citrate synthase activity, thus indicating that there are no significant differences in the number of mitochondria per milligram of protein obtained from the different age groups.

\subsection{Mitochondrial respiration}

All relevant mitochondrial respiratory parameters determined are shown in Table 1 (see also Fig. 2) and were measured with succinate as substrate. Respiratory rates using Complex I substrates were very reduced and thus prone to error when measured (data not shown). Due to this reason, we opted for only presenting data with succinate as substrate. The first observation is that testicular mitochondria have a lower oxygen consumption during state 4 , although generating approximately the same mitochondrial electrical potential (around $200 \mathrm{mV}$ ) when compared to mitochondria extracted from other rat tissues [22,23], but with similar values when compared to rat testicular cells [24] as observed in Table 2.

Younger cats presented a tendency to have a lower ADP/O ratio $(P=0.059)$ when compared with adult cats. The ADP/O ratio corresponds to the number of nanomoles of ADP phosphorylated by the reduction of 1 nanoatom of oxygen, and measures the efficiency of the mitochondrial phosphorylation system. The result suggests that testicular mitochondria from younger cats consume more oxygen
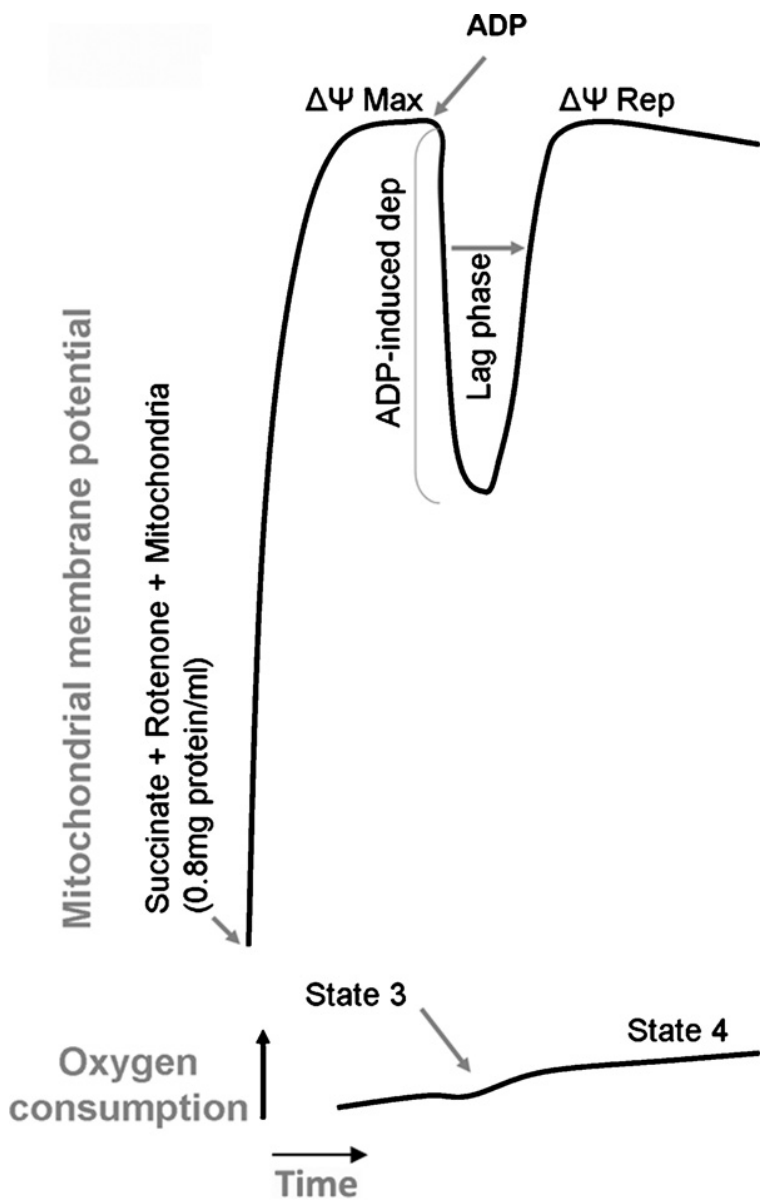

Fig. 2. Example of a record obtained with isolated mitochondria from cat testicular cells and principal parameters measured. $\Delta \Psi_{\mathrm{Max}}$, maximum mitochondrial electric potential; $\Delta \Psi_{\text {Rep }}$, repolarization potential. 
Table 2

Comparative analysis of bioenergetic parameters of succinate-energized mitochondria in different tissues.

\begin{tabular}{|c|c|c|c|c|c|c|}
\hline & State 3 (natoms $\mathrm{O} / \mathrm{min} / \mathrm{mg}$ prot) & State 4 (natoms $\mathrm{O} / \mathrm{min} / \mathrm{mg}$ prot) & RCR & $\mathrm{ADP} / \mathrm{O}$ & $\Delta \Psi_{\max }(\mathrm{mV})$ & $\Delta \Psi_{\text {rep }}(\mathrm{mV})$ \\
\hline Brain $^{a}$ & $98.82 \pm 5.32$ & $47.46 \pm 2.63$ & $2.28 \pm 0.09$ & $1.27 \pm 0.08$ & $-177.3 \pm 2.2$ & $-178.3 \pm 1.25$ \\
\hline Heart ${ }^{\mathrm{a}}$ & $145.95 \pm 3.56$ & $61.72 \pm 6.05$ & $3.38 \pm 0.09$ & $1.22 \pm 0.03$ & $-239.89 \pm 0.79$ & $-242.13 \pm 0.92$ \\
\hline Liver $^{\mathrm{b}}$ & $77.7 \pm 7.7$ & $16.9 \pm 0.6$ & $4.7 \pm 0.5$ & $1.7 \pm 0.1$ & $-224.0 \pm 1.28$ & $-221.9 \pm 1.63$ \\
\hline Kidney $^{\mathrm{a}}$ & $125.47 \pm 13.89$ & $60.51 \pm 12.37$ & $2.23 \pm 0.28$ & $1.05 \pm 0.12$ & $-213.09 \pm 1.09$ & $-213.13 \pm 1.95$ \\
\hline Testis (rat) ${ }^{c}$ & $31.30 \pm 1.52$ & $25.52 \pm 1.62$ & $1.27 \pm 0.05$ & $1.78 \pm 0.24$ & $-198.67 \pm 2.6$ & $-193.9 \pm 3.03$ \\
\hline Testis (domestic cat) & $22.67 \pm 1.59$ & $10.24 \pm 1.29$ & $2.21 \pm 0.21$ & $1.96 \pm 0.12$ & $-210.94 \pm 1.82$ & $-209.58 \pm 1.72$ \\
\hline
\end{tabular}

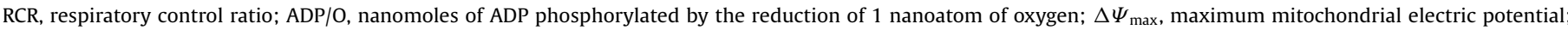
$\Delta \Psi_{\text {rep }}$, repolarization potential.

a Adapted from [23].

b Adapted from [22].

c Adapted from [24].

to phosphorylate the same amount of ADP, thus appearing to have a less efficient phosphorylation system.

RCR is the ratio between mitochondrial respiration during state 3 (active ATP production) and 4 (consumption of oxygen after ADP has been phosphorylated) and serves as a measure of mitochondrial coupling. Cat testicular mitochondria presented low RCR values suggesting some degree of uncoupling between oxidation of substrates and ADP phosphorylation, but no differences were observed between experimental groups.

\subsection{Mitochondrial electrical potential}

Transmembrane electrical potential $(\Delta \Psi)$ is the main component of the electrochemical gradient $\left(\Delta H^{+}\right)$, accounting for more than $90 \%$ of the total protonmotive force. Therefore, changes associated with $\Delta \Psi$ are of major importance in studies of mitochondrial oxidative phosphorylation. Fluctuations of $\Delta \Psi$ in mitochondrial preparations of different age groups were studied in the presence of glutamate-malate (GM) and succinate (Succ) plus rotenone and are registered in Table 1 (see also Fig. 2). We observed that the maximum developed membrane potential was increased in adult animals when compared with the younger animals group for both substrates $(P<0.05$ for GM and $P \leq 0.01$ for Succ). The same differences were observed at the repolarization level ( $\Delta \Psi$ re-established after ADP phosphorylation). No differences in the phosphorylation lag phase as well as in ADP-induced depolarization were observed. The lag phase is the time needed for mitochondria to recover to the initial steady state and corresponds to the period of ADP phosphorylation. The ADP-induced depolarization is a measurement of the amount of protons that pass through the ATP synthase in the presence of ADP. These results suggest no apparent differences between groups regarding the ATP synthase functionality.

We found a negative correlation $\left(r=(-) 0.701, R^{2}=0.491\right.$, $P \leq 0.001$ ) between the $\Delta \Psi$ generated by complex II substrates and animal age, which was also present when mitochondria were energized by complex I substrates (data not shown; Fig. 3). This correlation is also observed when the independent variable is testis weight, instead of age $\left(r=(-) 0.691 ; R^{2}=0.477, P \leq 0.001\right)$. These correlations indicate that when age/testis weight increase the mitochondrial transmembrane electric potential also increases, taking on more negative values. Through the curve estimation program on SPSS, we were able to determine the interpolation equation that better describes the behavior of mitochondrial potential according to the age of the animal: $Y=-[147.77 / X+(X \times 215.82)]$. This curve allowed us to predict the expected mitochondrial maximum potential at each age. Interestingly, the two animals that presented a much lower $\Delta \Psi$ than expected, thus deviating from the model when compared to age-matched animals, (isolated in the box, Fig. 3), had Feline Immunodeficiency Syndrome or testis alterations (smaller testes). This may suggest that conditions with the

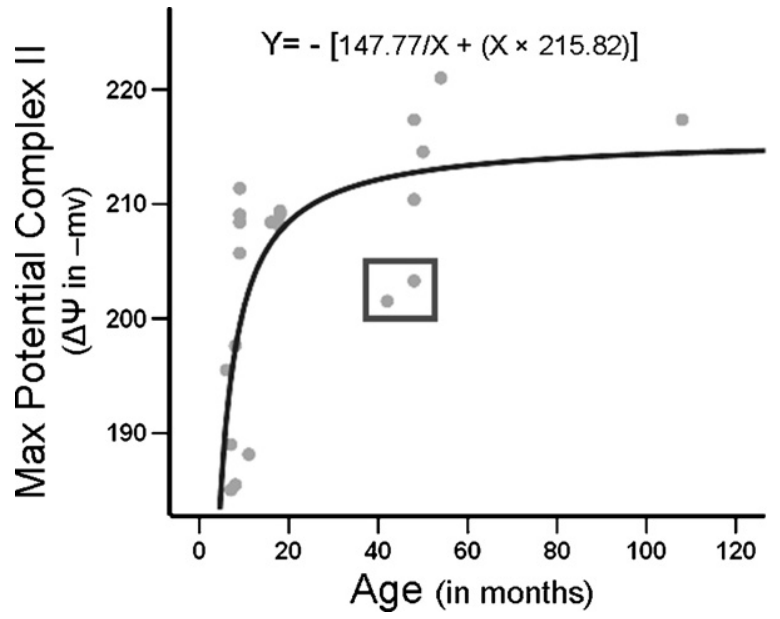

Fig. 3. Negative correlation $\left(r=(-) 0.701 ; R^{2}=0.491, P \leq 0.001\right)$ between $\Delta \Psi$ generated by complex II-substrates and age. The same can be found for $\Delta \Psi$ generated by complex I (not shown). One can determine the expected potential at each age using the interpolation equation $(Y=-[147.77 / X+(X \times 215.82)]$. The two animals in the box presented alterations (Feline immunodeficiency syndrome or smaller testes).

potential of reducing fertility presented a decreased mitochondrial transmembrane electrical potential.

\section{Discussion}

In aerobic living systems, oxidative phosphorylation activity can vary widely to adequately match ATP synthesis to energy demand according to physiological or pathological conditions. In contrast to short-term adaptation, which relies only on a flux modulation through every functional unit of mitochondrial oxidative phosphorylation, chronic adaptation to various rates of ATP consumption can also be achieved by modifying the number, morphology and location of these functional units [25,26].

During spermatogenesis, there are also adaptations to different levels of ATP expenditure. It has been previously described by several authors that the dependence of germ cells on glucose and lactate/pyruvate for energy metabolism keeps changing [27-28]. Spermatogonia, mature spermatozoa, and somatic Sertoli cells exhibit high glycolytic activity, whereas spermatocytes and spermatids produce ATP mainly by mitochondrial oxidative phosphorylation [28]. This difference may explain and/or be explained by differences found in mitochondrial germ cell morphology. During spermatogenesis at least three different types of mitochondria can be observed: the usual cristae-containing orthodox-type mitochondria in Sertoli cells, spermatogonia, preleptotene and leptotene spermatocytes; the intermediate form of mitochondria in leptotene, zygotene spermatocytes and spermatozoa; and the mitochon- 
dria condensed form in pachytene spermatocytes and spermatids [29].

Although a more detailed study with individual cell types was not possible given the low yield in terms of functional mitochondrial protein, the differences described between age groups can be explained by changes in testis cellularity. Younger cats present a lower mitochondrial electric potential and a reduced ADP/O ratio i.e. a decrease in phosphorylation efficiency, which may be due to higher spermatogonia-to-spermatocyte ratio with younger animals presenting proportionately less differentiated cells and more spermatogonia. These latter undifferentiated cells are located closer to arterial vessels, implying easier access to oxygen and nutrients [30], although having increased dependency on glycolysis to obtain energy $[25,27,28,30,31]$. Thus, mitochondria from spermatogonia do not need to perform phosphorylative oxidation very efficiently, and present the less efficient/active orthodox form of mitochondria. On the other hand, adult cats with a fully developed and active spermatogenesis present a very low spermatogonia-to-spermatocyte ratio with prevalence of the condensed and very active form on the isolated mitochondrial fraction [29].

As we can appreciate from the results, testicular mitochondria have different bioenergetic parameters when compared to mitochondria harvested from other tissues mitochondria such as the liver, brain, kidney or heart, especially when measuring state 3 and 4 respiration and RCR, this by using the same isolation protocols and in the same laboratory [22,23]. The discrepancy was not unexpected since other differences in mitochondrial activity have been observed between different tissues $[22,23]$ and between different type/localization of mitochondria within a certain kind of tissue [32]. The data strongly suggests that, while the use of liver mitochondria in toxicology studies is certainly important given the prominent role of this organ in substance clearance, the use of testicular mitochondria should be considered the model of election to test drugs affecting testicular cells through the mitochondrial pathway. For example, recently Hase et al. used liver mitochondria to test the effects of Atrazine in sperm [33] and, although our model does not deal with ejaculated sperm, it represents mitochondria isolated from several types of germinal cells including immature spermatozoa and therefore should be considered a more suitable model for these analysis. This system may also be used to test effects of environmental contaminants such as pesticides and herbicides. Permethrin, a popular synthetic pyrethroid insecticide used to control noxious insects in agriculture, forestry and households was suggested to cause mitochondrial membrane impairment in Leydig cells and disrupt testosterone biosynthesis [34]. In this study by Zhang and co-workers, the inner mitochondrial membrane in Leydig cells was disrupted and the cristae were replaced by a denser matrix. Methoxychlor, another pesticide used in many countries, has been shown to induce reproductive abnormalities in male rats, through induction of oxidative stress in the testis [35]. The system presented here could be used to verify alterations in the functionality of testicular mitochondria, in conjunction with the histological and enzymatic approaches used in the latter studies, revealing other possible alterations in the mitochondria induced by these toxicants. Another major aspect in environmental contaminants is the toxicity threshold. This may vary with species and with the tissue within the individual. Therefore, the use of this system could also serve to determine the toxicity threshold for testicular cells and in particular for felid testicular cells, solving a major problem when interpreting the possible effects of determined concentrations of toxicants found in tissues, blood or fur from an animal. Studies on xenobioticinduced reproductive system toxicity have increased in importance since some of the pesticides that were found to cause testis toxicity through mitochondria (such as DDE, a metabolite of DDT [11]) were already found in the hair, blood and tissues of wild felids [36] making these top of the food chain species possible targets.
Besides the mitochondrial differences observed in testicular tissue, age-dependent variations were also observed. These differences may have implications in the extrapolation of data from different age groups. One example of different drug behavior according to age may arise from drugs that accumulate in mitochondria according to their membrane potential (one example being the alkaloid Berberine; [37]), given that mitochondria from adult animals can accumulate a higher amount of drug, and therefore be more affected by its presence.

In conclusion, besides a basic insight into the energy production machinery of domestic cat testis, the results presented here also generate a practical and ethically acceptable model relying on material obtained routinely in veterinary clinics and considered a waste of neutering procedures. The present biological system may be useful to further test some of the drugs now being used to rescue fertility (such as antioxidants and energetic substrates) and their effect on germ cells and sperm, as well as the effects of environmental contaminants (such as pesticides and herbicides), many of which acting on mitochondria and interfering on the reproduction of wild animals. Finally, the results from the present investigation also supply an alternative model for studies relating reproductive function and mitochondrial bioenergetics in other carnivores.

\section{Conflict of interest statement}

None.

\section{Acknowledgments}

P.C. Mota would like to thank M. Sancha Santos and A. Moreno for continuous technical assistance and useful discussions. Also, a special thanks to all the veterinarians that supported this work through cat tissue donation. Paula C. Mota and Sandra Amaral were supported by the Portuguese Foundation for Science and Technology (SFRH/BD/23643/2005 and SFRH/18734/2004, respectively).

\section{References}

[1] Petit JM, Ratinaud MH, Cordelli E, Spanò M, Julien R. Mouse testis cell sorting according to DNA and mitochondrial changes during spermatogenesis. Cytometry 1995;19:304-12.

[2] França LR, Godinho CL. Testis morphometry, seminiferous epithelium cycle lengh, and daily sperm production in domestic cats (Felis catus). Biol Reprod 2003;68:1554-61.

[3] Pukazhenthi B, Wildt DE, Howard JG. The phenomenon and significance of teratospermia in felids. J Reprod Fertil 2001;57(Suppl.):423-33.

[4] Neubauer K, Jewgenow K, Blottner S, Wildt DE, Pukazhenthi BS. Quantity rather than quality in teratospermic males: a histomorphometric and flow cytometric evaluation of spermatogenesis in the domestic cat (Felis catus). Biol Reprod 2004; $71: 1517-24$.

[5] Blanco-Rodríguez J. DNA replication and germ cell apoptosis during spermatogenesis in the cat. J Androl 2002;23:484-90.

[6] Mota PC, Ramalho-Santos J. Comparison between different markers for sperm quality in the cat: Diff-Quik as a simple optical technique to assess changes in the DNA of feline epididymal sperm. Theriogenology 2006;65:1360-75.

[7] Cadenas E. Mitochondrial free radical production and cell signaling. Mol Aspects Med 2004;25:17-26.

[8] Darley-Usmar VM, Rickwood D, Wilson MT. Mitochondria-a practical approach. Oxford, England: IRL Press Limited; 1987. p. 1-16.

[9] Harris D. Bioenergetics at a glance. Oxford: Blackwell Science Ltd; 1995. p. 28-35.

[10] Shaha C. Modulators of spermatogenic cell survival. Soc Reprod Fertil Suppl 2007;63:173-86.

[11] Ferreira FM, Madeira VCM, Moreno AJ. Interactions of 2,2-bis( $p$-chlorophenyl)1,1-dichloroethylene with mitochondrial oxidative phosphorylation. Biochem Pharmacol 1997;53:299-308.

[12] Belyaeva EA, Dymkowska D, Wieckowski MR, Wojtczak L. Mitochondria as an important target in heavy metal toxicity in rat hepatoma AS-30D cells. Toxicol Appl Pharmacol 2008;231:34-42.

[13] Mohamed MK, Evans TC, Mottet NK, Burbacher TM. Effects of methyl mercury on sperm oxygen consumption. Acta Pharmacol Toxicol (Copenh) 1986;58:219-24.

[14] Facemire CF, Gross TS, Guillette Jr LJ. Reproductive impairment in the Florida panther: nature or nurture? Environ Health Perspect 1995;103(Suppl. 4):79-86. 
[15] Hinck JE, Schmitt CJ, Chojnacki KA, Tillitt DE. Environmental contaminants in freshwater fish and their risk to piscivorous wildlife based on a national monitoring program. Environ Monit Assess. doi:10.1007/s10661-008-0331-5.

[16] Siemieniuch MJ, Wocławek-Potocka I. Morphological features of the seminiferous epithelium in cat (Felis catus, L. 1758) testes. J Reprod Dev 2007;53:1125-30.

[17] Amaral S, Mota P, Rodrigues AS, Martins L, Oliveira PJ, Ramalho-Santos J. Testicular aging involves mitochondrial dysfunction as well as an increase in UCP2 levels and proton leak. FEBS Lett 2008;582:4191-6.

[18] Coore HG, Denton RM, Martin BR, Randle PJ. Regulation of adipose tissue pyruvate dehydrogenase by insulin and other hormones. Biochem J 1971;125:115-27.

[19] Estabrook RW. Mitochondrial respiratory control and the polarographic measurement of ADP:O ratio. Meth Enzymol 1967;10:41-7.

[20] Chance B, Williams GR. The respiration chain and oxidative phosphorylation. Adef Enzymol 1956;17:65-134.

[21] Kamo N, Muratsugu M, Hongoh R, Kobatake Y. Membrane potential of mitochondria measured with an electrode sensitive to tetraphenyl phosphonium and relationship between proton electrochemical potential and phosphorylation potential in steady state. J Membr Biol 1979;49:105-21.

[22] Teodoro J, Rolo AP, Oliveira PJ, Palmeira CM. Decreased ANT content in Zucker fatty rats: relevance for latered hepatic mitochondrial bioenergetics in steatosis. FEBS Lett 2006;580:2153-7.

[23] Moreira PI, Rolo AP, Sena C, Seiça R, Oliveira CR, Santos MS. Insulin attenuates diabetes-related mitochondrial alterations: a comparative study. Med Chem 2006;2:299-308.

[24] Amaral S, Mota PC, Lacerda B, Alves M, Pereira ML, Oliveira PJ, et al. Testicular mitochondrial alterations in streptozotocin-induced diabetic rats. Mitochondrion. doi:10.1016/j.mito.2008.11.005.

[25] Meinhardt A, Wilhelm B, Seitz J. Expression of mitochondrial marker proteins during spermatogenesis. Hum Reprod Update 1999;5:108-19.

[26] Nogueira V, Rigoulet M, Piquet M-A, Devin A, Fontaine E, Leverve MX. Mitochondrial respiratory chain adjustment to cellular energy demand. J Biol Chem 2001;276:46104-10.

[27] Bajpai M, Gupta G, Setty BS. Changes in carbohydrate metabolism of testicular germ cells during meiosis in the rat. Eur J Endocrinol 1998;138: 322-7.
[28] Erkkila K, Kyttanen S, Wikstrom M, Taari K, Hikim AP, Swerdloff RS, Dunkel L. Regulation of human male germ cell death by modulators of ATP production. Am J Physiol Endocrinol Metab 2006;290:1145-54.

[29] Martino C, Marcante F, Malorni W, Barcellona PS, Bellocci M, Silvestrini B. Morphological, histochemical and biochemical studies on germ cell mitochondria of normal rats. Cell Tissue Res 1979;196:1-22.

[30] Wenger RH, Katschinski DM. The hypoxic testis and post-meiotic expression of PAS domain proteins. Semin Cell Dev Biol 2005;16:547-53.

[31] Ruiz-Pesini E, Díez-Sánchez C, López-Pérez MJ, Enríquez JA. The role of mitochondria in sperm function:is there a place for oxidative phosphorilation $\mathrm{o}$ is a purely glycolytic process? Curr Top Dev Biol 2007;77:3-19.

[32] Lesnefsky EJ, Moghaddas S, Tandler B, Kerner J, Hoppel CL. Mitochondrial dysfunction in cardiac disease: ischemia-reperfusion, aging, and heart failure. J Mol Cell Cardiol 2001;33:1065-89.

[33] Hase Y, Tatsuno M, Nishi T, Kataoka K, Kabe Y, Yamaguchi Y, Ozawa S N., Natori $\mathrm{M}$, Handa H, Watanabe H. Atrazine binds to F1F0-ATP synthase and inhibits mitochondrial function in sperm. Biochem Biophys Res Commun 2008;366: 66-72.

[34] Zhang S-Y, Ito Y, Yamanoshita O, Yanagiba Y, Kobayashi M, Taya K, Li C Okamura A, Miyata M, Ueyama J, Lee C-H, Kamijima M, Nakajima T. Permethrin may disrupt testosterone biosynthesis via mitochondrial membrane damage of leydig cells in adult male mouse. Endocrinology 2007;148(8): 3941-9.

[35] Latchoumycandane C, Mathur PP. Effect of methoxychlor on the antioxidant system in mitochondrial and microsome-rich fractions of rat testis. Toxicology 2002;176:67-75.

[36] Mora MA, Laack LL, Lee MC, Sericano J, Presley R, Gardinali PR, Gamble LR, Robertson S, Frank D. Environmental contaminants in blood, hair and tissues of ocelots from The Lower Rio Grande Valley, TX, 1986-1997. Environ Monit Assess 2000;64:477-92.

[37] Pereira GC, Branco AF, Matos JA, Pereira SL, Parke D, Perkins EL, Serafim TL Sardão VA, Santos MS, Moreno AJ, Holy J, Oliveira PJ. Mitochondrially targeted effects of berberine [Natural Yellow 18, 5,6-dihydro-9,10-dimethoxybenzo(g)1,3-benzodioxolo(5,6-a) quinolizinium] on K1735-M2 mouse melanoma cells: comparison with direct effects on isolated mitochondrial fractions. J Pharmacol Exp Ther 2007;323:636-49. 